\title{
Clinical Effect of a New Type of Transpedicular Reducer for Fracture Reduction via Pedicle and Bone Grafting Combined With Pedicle Screw Fixation for Thoracolumbar Burst Fractures
}

\section{menghan cai}

Zunyi Medical College Affiliated Hospital: Affiliated Hospital of Zunyi Medical College

\section{Zhijun Xin}

Zunyi Medical College Affiliated Hospital: Affiliated Hospital of Zunyi Medical College

\section{Weijun Kong}

the affiliated hospital of zunyi medical university

Qian Du

Zunyi Medical College Affiliated Hospital: Affiliated Hospital of Zunyi Medical College

Wenjun Ji

Zunyi Medical College Affiliated Hospital: Affiliated Hospital of Zunyi Medical College

Fujun Wu

Zunyi Medical College Affiliated Hospital: Affiliated Hospital of Zunyi Medical College

Jin Li

Zunyi Medical College Affiliated Hospital: Affiliated Hospital of Zunyi Medical College

Jialin $\mathrm{He}$

Zunyi Medical College Affiliated Hospital: Affiliated Hospital of Zunyi Medical College

Wenbo Liao ( $\sim 2478406376 @ q q . c o m$ )

The Affiliated Hospital of Zunyi Medical University

\section{Research article}

Keywords: burst fracture, thoracolumbar spine, transpedicular reducer, allogeneic bone, minimally invasive spine surgery

Posted Date: January 5th, 2021

DOl: https://doi.org/10.21203/rs.3.rs-138943/v1

License: (c) (1) This work is licensed under a Creative Commons Attribution 4.0 International License. Read Full License 


\section{Abstract}

\section{Background}

Short-segment transpedicular screw fixation is a common method for the treatment of thoracolumbar burst fractures (TBFs). When it is used, the anterior middle columns of the fractured vertebral body lack good support, resulting in fractured vertebral bodies decreased height and difficult to reduct. Therefore,the purpose of this study was to evaluate the clinical effect of a new type of transpedicular reducer that we designed for fractured vertebral body reduction and bone grafting in the treatment of TBFs.

\section{Methods}

A total of 9 patients with TBFs who agreed to be treated with the new transpedicular reducer for fracture reduction via pedicle and bone grafting combined with pedicle screw fixation were retrospectively analysed. We measured the anterior and middlel heights of the injured vertebrae, the ratios of the anterior and middlel heights of the injured vertebral body to the respective heights of the adjacent uninjured vertebral bodies (AVBHr and MVBHr, respectively), and the Cobb angle of patients at different stages before and after surgery, and evaluated the distribution of bone grafts and bone healing 3 days and 12 months after the operation.

Results

The anterior height of the injured vertebrae before the operation; after application of the transpedicular reducer; and 3 days, 3 months, 6 months and 12 months after the operation were $17.56 \pm 3.74 \mathrm{~mm}$; $27.70 \pm 2.53 \mathrm{~mm}$; and $29.08 \pm 2.52 \mathrm{~mm}, 28.36 \pm 1.93 \mathrm{~mm}, 28.12 \pm 1.42 \mathrm{~mm}$, and $27.96 \pm 0.72 \mathrm{~mm}$, respectively. The mid-heights of the injured vertebrae were $21.36 \pm 4.20 \mathrm{~mm} ; 26.74 \pm 1.00 \mathrm{~mm}$; and $27.70 \pm 2.01 \mathrm{~mm}, 27.05 \pm 2.45 \mathrm{~mm}, 26.94 \pm 1.84 \mathrm{~mm}$, and $26.83 \pm 2.45 \mathrm{~mm}$, respectively. The Cobb angles of the injured vertebrae were $3.80 \pm 1.44^{\circ} ; 1.26 \pm 1.00^{\circ}$; and $0.72 \pm 0.70^{\circ}, 1.03 \pm 0.65^{\circ}, 1.12 \pm 0.63^{\circ}$, and $1.34 \pm 0.56^{\circ}$, respectively. The allogeneic bones were distributed in the anterior and middle columns 3 days after the operation, and the bone had healed well 12 months after the operation.

\section{Conclusion}

The new transpedicular reducer has a good reduction, allogeneic bone support, and clinical treatment effect for TBFs through pedicle fracture reduction and bone grafting combined with pedicle screw fixation.

\section{Background}

Thoracolumbar burst fractures (TBFs) are one of the most common forms of spinal trauma in clinical practice. Usually, the axial compressive force on the centre column collapses the bone and causes the front and centre support columns to fail. Then, burst fracture will occur [1]. Most of these fractures (70\%) occur at the thoracolumbar junction (Th11-L2) [2]. In young patients, falls from heights, traffic accidents, 
and sports injuries are the most common causes of vertebral fractures [2]. Simple falls are the most common cause of incomplete burst fractures in the elderly [3]. In the AOSpine thoracolumbar spine injury classification system, burst fractures are classified as A3 or A4, depending on whether one or two end plates are damaged ( $A 3$ involves a single endplate fracture of the posterior wall of the vertebral body; A4 involves the upper and lower endplates and posterior wall of the vertebral body) [4]. The sequelae of these injuries can be devastating, including paralysis, pain, deformity and loss of function [5-8].

The purpose of TBF treatment is to stabilize the spine, prevent short-term and long-term deformities, prevent neurological decline, and improve clinical outcomes [9]. Nonsurgical treatment is ineffective for most patients with burst fractures, and there may be a longer immobilization time and failure to restore the normal sagittal position [10]. Rapid surgery not only can restore the sagittal position more reliably in some cases [11-13] but can also restore nerve function more effectively to recover as soon as possible.

Clinically, the most widely used surgical method for the treatment of TBFs is short-segment fixation with pedicle screws, and this surgical treatment has good results. However, domestic and foreign clinical studies have found that reduction of short-segment fixation with pedicle screws fails [14-15], mainly because only the pedicle screw instrument is used to indirectly reduce the fractured vertebrae through distraction, which will cause insufficient reduction of the depressed endplate [16], and failure to reposition the injured vertebrae after short-segment transpedicular screw fixation without bone grafting will result in the formation of a "hollow-like" vertebral body [17], which in turn will fail to provide enough support and stimulation to heal fractures inside the vertebral body. However, the "hollow-like" vertebral body with incomplete bone healing will further decrease the height of the injured vertebral body under the action of a slight external force, and may later lose the vertebral body and even fracture again, causing instability [18-20], As a result, the structural integrity of the anterior and middle column of the spine and the stability of the load are reduced [21-22], and kyphosis is aggravated [23-25]. Due to the lack of support for the injured vertebrae due to this operation, the fractured vertebral body will not heal well, and consequently, bone grafting is required for the "hollow-like" vertebral body.

To reduce the height of the injured vertebrae, correct kyphosis, and promote healing of the injured vertebrae, we designed a new type of transpedicular reducer according to the anatomical nature of the thoracic and lumbar pedicles, which can better restore the height of the vertebral body by manipulating the mechanical force. In addition, we intraoperatively implanted allogeneic bone and prospectively studied the clinical results of 9 cases of thoracolumbar vertebral burst fracture at the First Affiliated Hospital of Zunyi Medical University from August 2019 to March 2020 using the new transpedicular reducer through pedicle fracture reduction and bone grafting combined with pedicle screw fixation.

\section{Method}

\subsection{Inclusion criteria:}


(1) vertebral burst fracture confirmed by X-ray examination or CT scan; (2) AO classification as A3 or A4 burst fracture; (3) no serious heart, brain or lung problems; (4) no surgical contraindications, such as infections and blood clotting disorders.

\subsection{Clinical data}

Nine patients with TBFs met the eligibility criteria for fracture reduction using the new transpedicular reducer via pedicle and bone grafting combined with pedicle screw fixation. They included 2 female and 7 male patients, ranging in age from 33 to 55 years (mean: 47.2 years). Among the fractures, 2 cases were caused by traffic accident injuries and 7 by falling from height. The fractured vertebrae were T11 ( 2 cases), T12 (2 cases), LI (4 cases), and L2 (1 case); furthermore, 6 cases were type A3 and 3 cases were type A4. The posterior wall of the vertebral body remained largely intact. No neurological deficit was seen.

\subsection{New transpedicular reducer 2.3.1 Structural design}

A new type of transpedicular reducer (Chinese patent number: ZL 20192 1561649.5) (as shown in Fig. 1) was designed. It includes a knob (1), a fixed sleeve (2), a transmission rod (3), a pin (4), a movable pull rod (5), a fastening nut (6), a fixed pull rod (7) and a support assembly, the support assembly includes a link mechanism (8), a rivet (9), and a support plate (10). (There are two support plates), turning knob 1 drives transmission rod 3 to move, thereby driving movable rod 5 to move, and movable rod 5 moves to drive linkage mechanism 8 to contract or expand, thereby driving support plate 10 to open or close, which can open up and down or left and right.

\subsubsection{Operational technical points}

First, establish a path through the pedicle to reach the centre of the fractured vertebral body, and implant the new transpedicular reducer in its unexpanded state through the path to make it reach the proper position in the vertebral body. Then, turn the knob to expand the reducer and make it burst. The fractured vertebral body restores its height and shape and finally rotates the knob to close the reducer to withdraw from the vertebral body. See Fig. 2.

\subsection{Operation}

All the patients were intubated under general anaesthesia, with bent hips, bent knees, bowed waist and a prone position on the operating bed, as well as with moderate overextension of the trunk to increase the lamina space for the operation. The two iliac abdomens were placed on cushioned support for fixation and the abdomens were suspended to reduce abdominal pressure and reduce intraspinal venous plexus bleeding. Regular disinfection was employed, and sterile towels were spread, slightly laterally in bilateral marked points at approximately $0.5 \mathrm{~cm}$. Needle biopsy was applied to the pedicle centre, under the $\mathrm{C}$ arm with an oblique perspective to adjust the needle position and direction satisfactorily after fixed needle positioning, in order to guide the needle puncture point in the centre-cut skin and subcutaneous tissue. 
The fascia was cut with a high frequency electric knife, followed by periosteal stripping on both sides of the shaft, electric coagulation and gauze tamponade haemostasis, which revealed the spinal segment, vertebra, and articular process. On both sides of vertebral pedicle, the positioning needle was placed into the needle point, from the perspective of the $C$ arm machine. The position and direction of the satisfactorily enlarged hole was adjusted, from the vertebral segment. Four pedicle screws with a suitable diameter and length were installed, and $C$ arm fluoroscopy was used to ensure that the pedicle screw position and direction were satisfactory. After the needle was used to place the pedicle into the needle point and after $\mathrm{C}$ arm fluoroscopy revealed that the location was accurate, the injured vertebral pedicle was used to establish an open channel. The bone graft in the $C$ arm fluoroscopy guided vertebrae reset the device implanted in a central location; the handle was reset clockwise, and the device was reset in the open, bottom plate, and then the rotating handle was rotated anti-clockwise. The reset was slowly exited. The height of the injured vertebra was recovered under the $\mathrm{C}$ arm. The defect was filled with allogeneic bone granules implanted into the vertebra through the bone graft channel of the injured vertebra. Prebent titanium rods were installed and properly propped and fixed. $\mathrm{C}$ arm fluoroscopy showed that the pedicle screw position and direction, as well as the injured vertebral body, were satisfactory. Next, the horizontal connecting rod was installed. A large amount of normal saline was used to wash the wound surface. No active bleeding was detected, and the gelatine sponge was covered. After the dressing, the instruments and brain cotton were checked, a negative pressure drainage tube was placed, the incision was closed layer by layer, a sterile dressing was wrapped and fixed, and the operation was completed.

\subsection{Patient evaluation}

\subsubsection{Measurement}

The injured thoracolumbar vertebrae were measured before the operation; after reduction with the new transpedicular reducer; and 3 days, 3 months, 6 months and 12 months after the operation. Surgimap software was used to measure and determine the height of the injured vertebral body.

\subsubsection{Measurement of the anterior height and ratio of the injured vertebrae (AVBHr); (see Fig. 3a).}

\subsubsection{Measurement of the middle height and ratio of the injured vertebrae (MVBHr); (see Fig. 3b).}

\subsubsection{Measurement of the Cobb angle of the injured vertebrae (see Fig. 3c).}

\section{Statistical Analysis}

SPSS 18.0 statistical software was used for analysis. Data are expressed as the mean \pm standard deviation (+ $s$ ). Measurements before and after surgery were analysed by the paired $t$ test for data 
collected preoperatively and 3 days, 3 months, 6 months and 12 months postoperatively. Data were compared with a significance level of $a=0.05$. $P<0.05$ was considered statistically significant.

\section{Results}

\subsection{Perioperative situation}

All subjects underwent successful transpedicular vertebral body reduction and allograft surgery, consisting of a total of nine vertebral bodies. The mean operative time was $120.3 \pm 22.6 \mathrm{~min}$. The patients became active 2 to 3 days after bed rest. No signs of nerve root stimulation, neurological impairment, infection or embolism were observed throughout the operation or after the operation.

\subsection{Measurement results for the vertebra height and Cobb angle}

The anterior height and central height of injured vertebrae, AVBHr,MVBHr, Cobb angle and Cobb angle correction of 9 cases with new restorer pedicle reduction and fractures and bone graft combined with pedicle screw fixation in TBF patients preoperatively, after application of vertebral body fracture restoration, and postoperatively at 3 days, 3 months, 6 months and 12 months are shown in Table 1 .

According to the statistical analysis, the anterior vertebral height, central vertebral height, $\mathrm{AVBHr}, \mathrm{MVBHr}$ and Cobb angles after the application of the vertebral fracture reduction device and 3 days, 3 months, 6 months and 12 months after the operation were each significantly different from the corresponding values before the operation $(P<0.05)$, but the differences among the postoperative data points were not significant ( $\mathrm{P} \otimes 0.05)$.

\subsection{Observational results of bone grafting}

During the operation, $4 \sim 9 \mathrm{~g}$ allograft bone was used to fill in the vertebral body (the average amount of bone graft was $5.4 \mathrm{~g}$ ), and there were no complications, such as pedicle rupture and intravertebral haematoma. Three days after surgery, the allograft was evenly wedged in the anterior and medial columns (see Fig. 4). CT re-examination 12 months after the operation showed that the allograft bone that filled the anterior and middle columns was absorbed, and no defects were found; moreover, the trabecular structure was visible in the cancellous bone, and there was good bone healing (supporting the fractured vertebra) as well as a good therapeutic effect.

\subsection{Typical cases}

The patient, a 32-year-old male, had a burst fracture of the L1 vertebra due to a fall, as shown in Fig. 5.

\section{Discussion}


TBFs are clinically common. Spinal fractures usually occur in the thoracolumbar segment, and burst fractures that occur at the thoracic-lumbar junction (T11-L2) account for $70 \%$ of fractures [2]. A burst fracture is the result of a compression mechanism or is part of an excessive bending, extension or rotation injury [26]. The front and centre columns cannot be supported due to axial loading [27-28]. The transition from the less mobile thoracic spine and its associated ribs and sternum to the more mobile lumbar spine makes the thoracolumbar junction (T11-L2) a large area of biomechanical stress. The imaging features are rupture of the posterior wall of the vertebral body, retrograde entry of the posterior edge of the vertebral body into the lumen, a decrease in the height of the vertebral body and an increase in the distance between the pedicles. The cause of this injury is usually traffic accidents, sports injuries or falls. Therefore, from a biomechanical or neurological point of view, many people consider burst fractures to be unstable. Burst fracture injuries are classified as A3 or A4 in the AOSpine thoracolumbar spine injury classification system. The objectives of treatment after a TBF are to stabilize the spine, prevent nervous system deterioration, restore sagittal balance, maintain as much segmental activity as possible with as little tissue damage as possible, and mobilize the patient as quickly as possible. Conservative treatment includes bed rest and reduced posture and orthotics, which may help relieve pain for weeks or months. Conservative treatment of fractures has been shown to be useful in most stable fractures [10.29-32] but not in all cases, and long-term bed rest is associated with a higher incidence of bedsores, pneumonia, venous thromboembolism, and even death [33]. Compared with nonsurgical methods, surgical treatment of thoracolumbar fractures does provide some advantages, especially for patients who cannot tolerate orthotics or plaster orthotics for several months, such as patients with multiple limb injuries, skin lesions, obesity, etc. [11]. Therefore, in the present study, patients with contraindications to surgery were excluded, and surgical treatment was recommended for the remaining patients. Surgical decompression can also be more reliable and effective in removing damaged spinal canals, restoring neurological function and improving rehabilitation. In 1984, Denis et al. conducted a retrospective comparison between the surgical and nonsurgical treatment of 52 cases of blowout fractures without neurological defects and found that all the patients treated with surgery had no relevant disability and returned to full-time work, while $25 \%$ of the patients treated without surgery were unable to return to full-time work [34]. In addition, neurological problems were reported in $17 \%$ of nonsurgical patients. Siebenga et al. concluded that surgical treatment not only had better clinical outcomes but was also more cost-effective than nonsurgical treatment [35]. Two other large systematic evaluations [36-37] showed that early surgery for thoracolumbar fractures was associated with reduced complications and shorter hospital and ICU stays.

Surgical treatment of TBFs varies with many factors. The shape of the fracture, the state of the nervous system, and the surgeon's preference all play important roles in determining the surgical procedure. Shortsegment pedicle screw fixation is now widely used and can be performed in a minimally invasive manner. This operation can effectively reconstruct the injured vertebra and enhance the stability of the anterior central column [38-39]. In addition, the surgical method has a low incidence and few complications [18]. However, the acknowledged disadvantages of this procedure are early reduction failure and recurrent kyphosis [18.40-41]. his is probably because posterior pedicle screw fixation alone does not provide enough support to heal the fractured vertebra without the assistance of anterior column reconstruction. 
Posterior pedicle fixation through the short segment of the vertebral pedicle involves homeopathic compression of the injured vertebra to repair the fractured injured vertebra, but this homeopathic pressure cannot repair the compressed cancellous bone in the injured vertebra, thus forming a "hollow" vertebra [18]. Therefore, placing these screws directly onto the vertebrae without reduction may weaken the vertebrae, affecting subsequent reduction of the fracture and possibly leading to fracture displacement. Moreover, failure to perform targeted bone grafting and filling of the local "eggshell-like" cavity formed after the reduction of the injured vertebra will lead to further loss of vertebral height. Therefore, we designed a new transpedicular reducer to treat compressibility and blowout fractures. According to our experimental research, application of the new transpedicular reducer in the treatment of vertebral burst can recover the anterior and middle height of injured vertebral bodies well, from preoperative values of $17.56 \pm 3.74 \mathrm{~mm}$ and $21.36 \pm 4.20 \mathrm{~mm}$ to $27.96 \pm 0.72 \mathrm{~mm}$ and $26.84 \pm 2.45 \mathrm{~mm}$, respectively, at the last follow-up; both increases were statistically significant. The Cobb angle decreased from $3.80 \pm 1.44^{\circ}$ before surgery to $1.34 \pm 0.56^{\circ}$ at the last follow-up, indicating that the Cobb angle decreased significantly after surgery, greatly correcting kyphosis.In general, the new transpedicular reducer, in addition to being very good at restoring the height of the vertebral body and correcting kyphosis, allows the injured vertebra to remain approximately in the corrected spinal position for a longer period of time after surgery.

Because the trabecular bone cannot be completely restored to the original callus structure after reduction, there will be a large space, which will directly lead to the loss of vertebral height in the later stage. Over the past decade, several studies have shown that reinforcing fractured vertebrae with absorbable bone cement can enhance fracture healing and prevent implant failure. However, the increase in bone cement is also a controversial area. Polymethacrylate (PMMA) is commonly used in vertebroplasty (VP) and balloon kyphoplasty (BK) for the treatment of osteoporosis and fresh thoracolumbar fractures. However, PMMA has been reported to be associated with undesirable characteristics, such as a high temperature setting, possible damage to local nerve and vascular structures, inadequate bone fusion and a severe stiffness mismatch with bone, resulting in subsequent adjacent fractures and even vertebral restenosis [42]. Moreover, the leakage rate is high (7-10\%). It has been reported that distal cement emboli enter the cardiac cavity and pulmonary system [43-44].PMMA is also non-absorbable, meaning that bone cement is retained rather than gradually replaced by biological tissue, which has a particularly adverse effect on young people. As a result, people are now also looking for a new implant to minimize the incidence of complications. Cao et al. reported that allograft bone implantation in thoracolumbar fractures can effectively correct the Cobb angle and the height of the injured vertebral front and reduce the degree of the injured vertebral defect [45]. Therefore, we applied the new transpedicular reducer and filled the damaged vertebral cavity with allograft bone through the bone graft channel, which effectively restored the vertebral bone structure and avoided leakage caused by the use of bone cement. The CT results of the patients 12 months after the operation showed that the allograft was evenly distributed in the front and middle columns in a wedge shape, some allografts were absorbed, no defects were found, and trabecular structures were visible in the cancellous bone.

In summary, the new transpedicular reducer, through minimally invasive transpedicular channel implantation, can address the patient's disease with minimal trauma. Additionally, because it uses the 
lever-regulating principle, a minimally invasive channel into the vertebral body can even open in two directions, increase the contact surface of the stent surface with the bone tissue interface open, in order to solve the problem posed by existing techniques that do not provide a support surface with the bonetissue stress interface. The new transpedicular reducer can also provide uniform support to repair the burst vertebral body fracture and restore good controllability (according to the actual need) of the reset height and is easy to operate. In addition, allogeneic bone implantation enables fractured vertebrae to heal well and can adequately support the injured vertebrae, with a good treatment effect.

\section{Conclusion}

The new transpedicular reducer effectively uses the lever principle to provide opening support as well as folding and withdrawing in a very small space. Its compact structure can meet the requirements of minimally invasive surgery in medical treatment and greatly improve the work efficiency. The current study showed that the treatment of TBFs via the new transpedicular reducer for pedicle and bone grafting combined with pedicle screw fixation is effective.

\section{Declarations}

\section{Acknowledgement}

We would like to acknowledge the support from the "Joint Foundation of GuiZhou, China (Grant No. Qian Ke He LH Zi [2014]7600)”,"Science and Technology Support Plan of GuiZhou Science and Technology Department (Qian Ke He Support [2019] 2812)","the National Natural Science Foundation of China (82060415)"and the reviewers for their helpful comments on this paper.

Funding Supported by the Joint Foundation of Guizhou, China (Grant No. Qian Ke He LH Zi [2014] 7600),Science and Technology Support Plan of GuiZhou Science and Technology Department (Qian Ke He Support [2019] 2812) and the National Natural Science Foundation of China (82060415)

Conflicts of interest Each author certifies that he or she, or a member of his or her immediate family, has no commercial association (i.e., consultancies, stock ownership, equity interest, patent/licensing arrangements, etc.) that might pose a conflict of interest in connection with the submitted manuscript.

Ethics approval Our study involving human had signed informed consent. This study was designed in accordance with the Declaration of Helsinki and approved by the ethics committee of The Affiliated Hospital of Zunyi Medical University.

Consent to participate Our study involving human subjects was performed with signed informed consent from all participants.

Consent for publication Not applicable

Availability of data and material Not applicable 
Code availability Not applicable

\section{References}

1. Crawford NR, Dickman CA. Construction of local vertebral coordinate systems using a digitizing probe. Technical note. Spine. 1997;22(5):559-63. https://doi.org/10.1097/00007632-19970301000020.

2. Reinhold M, Knop C, Beisse R, et al. Operative treatment of traumatic fractures of the thoracic and lumbar spinal column. Part I: epidemiology. Der Unfallchirurg. 2009;112(1):33-42,44https://doi.org/10.1007/s00113-008-1524-7

3. Josten C, Heyde CE, Spiegl UJ. Complex pathologies of the spine: trauma meets degeneration. Zeitschrift fur Orthopadie und Unfallchirurgie. 2016;154(5):440- https://doi.org/10.1055/s-0042108344

4. Vaccaro AR, Oner C, Kepler CK, et al. AOSpine thoracolumbar spine injury classification system: fracture description, neurological status, and key modifiers. Spine (Phila Pa 1976). 2013;38:20282037. https://doi.org/10.1097/BRS.0b013e3182a8a381.

5. Diaz JJ Jr, Cullinane DC, Altman DT, et al. Practice management guidelines for the screening of thoracolumbar spine fracture. J Trauma. 2007;63:709-18. https://doi.org/10.1097/TA.0b013e318142d2db

6. Rampersaud YR, Annand N, Dekutoski MB. Use of minimally in- vasive surgical techniques in the management of thoracolumbar trauma. Spine. 2006;3:S96-102. https://doi.org/10.1097/01.brs.0000218250.51148.5b.

7. Gertzbein SD. Scoliosis Research Society: multicenter spine frac- ture study. Spine. 1992;17:528-40. https://doi.org/10.1097/00007632-199205000-00010.

8. Levine A, McAfee P, Anderson P. Evaluation and emergent treat- ment of patients with thoracolumbar trauma. Instr Course Lect.1995;44:33-45.

9. Parker JW, Lane JR, Karaikovic EE, et al. Successful short-segment instrumentation and fusion for thoracolumbar spine fractures: a consecutive 41/2-year series. Spine. 2000;25:1157-70. https://doi.org/10.1097/00007632-200005010-00018.

10. Dai LY, Jiang LS, Jiang SD. Conservative treatment of thoracolum- bar burst fractures: a long-term follow-up results with special refer- ence to the load sharing classification. Spine. 2008;33:2536-44. https://doi.org/10.1097/BRS.0b013e3181851bc2.

11. Wood KB, Bohn D, Mehbod A. Anterior versus posterior treatment of stable thoracolumbar burst fractures without neurologic deficit: a pro- spective, randomized study. J Spinal Disord Tech. 2005;18:S15-23.

12. Cantor JB, Lebwohl NH, Garvey T, et al. Nonoperative management of stable thoracolumbar burst fractures with early ambulation and bracing. Spine. 1993;18:971-6. https://doi.org/10.1097/00007632-199306150-00004. 
13. Chipman JG, Deuser WE, Beilman GJ. Early surgery for thoraco- lumbar spine injuries decreases complications. J Trauma. 2004;56: 52-7. https://doi.org/10.1007/s00586-018-5601-5.

14. Butt M.F, Farooq M, Mir B, Dhar AS. Hussain, and M. Mumtaz. Management of unstablethoracolumbar spinal injuries by posterior short segment spinal fixatio. International Orthopaedics. 2007; 31(2):259- https://doi.org/10.1007/s00264-006-0161-4.

15. Mü Iler U, Berlemann U, Sledge J, Schwarzenbach O. Treatment of thoracolumbar burst fractures without neurologic deficit by indirect reduction and posterior instrumentation: bisegmental stabilization with monosegmental fusion. Eur Spine J. 1999;8(4):284-9 https://doi.org/10.1007/s005860050175.

16. Fredrickson BE, Edwards WT, Rauschning W, Bayley JC, Yuan HA. Vertebral burst fractures: an experimental, morphologic, and radiographic study. Spine. 1992;17(9):1012-21. https://doi:10.1097/00007632-199209000-00002.

17. McCormack T, Karaikovic E, Gaines RW. The load sharing classification of spine fractures. Spine. 1994. 19(15): 1741- https://doi.org/10.1097/00007632-199408000-00014.

18. Wang XY, Dai LY, Xu HZ, Chi YL. The load-sharing classification of thoracolumbar fractures: an in vitro biomechanical validation. Spine. 2007;32(11):1214https://doi.org/10.1097/BRS.0b013e318053ec69.

19. Vaccaro AR, Zeiller SC, Hulbert RJ, et al. The thoracolumbar injury severity score: a proposed treatment algorithm. J Spinal Disord Tech. 2005;18(3):209-

20. Machino M, Yukawa Y, Ito K,et al. Posterior ligamentous complex injuries are related to fracture severity and neurological damage in patients with acute thoracic and lumbar burst fractures. Yonsei Med J. 2013;54(4):1020- https://doi.org/10.3349/ymj.2013.54.4.1020.

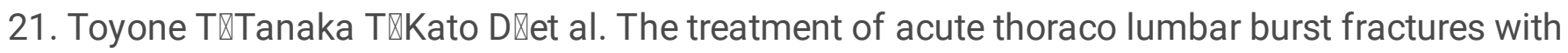
transpedicular intracorporeal hydroyap atite grafting following indirect reduction and pedical screw fixation: a prospective study. Spine. 2006;31(7):E208-

22. Zhang XD, Fang JL, Zhuang RJ, et al. Analysis of concurrent intravertebral vacuum sign in thoracolumbar fractures after posterior internal fixation. Zhong guo Gu Shang / China J Orthop Trauma. 2011;24(7):557-

23. Tezeren G, Kuru I. Posterior fixation of thoracolumbar burst fracture: short segment pedicle fixation versus long segment instrumentation. J Spinal Disord Tech. 2005;18(6):485https://doi.org/10.1097/01.bsd.0000149874.61397.38.

24. Altay M, Ozkurt B, Aktekin CN, et al. Treatment of unstable thorac olumbar junction burst fractures with short or long segment posterior fixation in magerl type fractures. Eur Spine J. 2007;16(8):1145https://doi.org/10.1007/s00586-007-0310-5.

25. Li X, Wang YP, Qiu GX, et al. Systematic review of posterior short segment pedicle screws fixation with or without fusion for thoracol umbar burst fractures. Zhongguo Gu Shang/China J Orthop Trauma. 2011;24(1):5- 
26. Magerl F, Aebi M, Gertzbein SD, Harms J, Nazarian S. A comprehensive classification of thoracic and lumbar injuries. Eur Spine J. 1994;3:184-201. https://doi.org/10.1007/BF02221591.

27. Benson DR, Burkus JK, Montesano PX, Sutherland TB, McLain RF. Unstable thoracolumbar and lumbar burst fractures treated with the AO fixateur interne. J Spinal Disord. 1992;5:335-43. https://org/10.1097/00002517-199209000-00012.

28. Crawford NR, Dickman CA. Construction of local vertebral coordinate systems using a digitizing probe. Tech Note Spine. 1997;22:559-63. https://doorg/10.1097/00007632-199703010-00020.

29. Mumford J, Weinstein JN, Spratt KF, et al. Thoracolumbar burst fractures. The clinical efficacy and outcome of nonoperative man- agement. Spine. 1993;18:955-70.

30. Shen WJ, Shen YS. Nonsurgical treatment of three-column thoraco- lumbar junction burst fractures without neurologic deficit. Spin. 1999;24:412-5. https://doi.org/10.1097/00007632-19990215000024.

31. Knight RQ, Stornelli DP, Chan DP, et al. Comparison of operative versus nonoperative treatment of lumbar burst fractures. Clin Orthop Relat Res. 1993;293:112-21.

32. Kraemer WJ, Schemitsch EH, Lever J, et al. Functional outcome of thoracolumbar burst fractures without neurological deficit. J Orthop Trauma. 1996;10:541-4. https://doi.org/10.1097/00005131$199611000-00006$.

33. Khare S, Sharma V. Surgical outcome of posterior short segment trans-pedicle screw fixation for thoracolumbar fractures. J Orthop. 2013;10:162-7.

34. Denis F, Armstrong GW, Searls K, Matta L. Acute thoracolumbar burst fractures in the absence of neurologic deficit. A comparison between operative and nonoperative treatment. Clin Orthop Relat Res. 1984;(189):142-

35. Siebenga J, Segers MJ, Leferink VJ, Elzinga MJ, Bakker FC, Duis HJ, Rommens PM, Patka P. Costeffectiveness of the treatment of traumatic thoracolumbar spine fractures: Nonsurgical or surgical therapy. Indian J Orthop. 2007;41(4):332- https://doi.org/10.4103/0019-5413.36997.

36. Rutges JP, Oner FC, Leenen LP. Timing of thoracic and lumbar fracture fixation in spinal injuries: a systematic review of neurological and clinical outcome. Eur Spine J. 2007;16:579-587. https://doi.org/10.1007/s00586-006-0224-7.

37. Xing D, Chen Y, Ma JX, et al. A methodological systematic review of early versus late stabilization of thoracolumbar spine Eur Spine J. 2013;22:2157-2166.35. https://doi.org/10.1007/s00586-0122624-1.

38. Magerl F, Aebi M, Gertzbein SD, Harms J, Nazarian S. A comprehensive classification of thoracic and lumbar injuries. Eur Spine J. 1994;3(4):184- https://doi.org/10.1007/BF02221591.

39. Cho DY, Lee WY, Sheu PC. Treatment of thoracolumbar burst fractures with polymethyl methacrylate vertebroplasty and short- segment pedicle screw fixation. Neurosurgery. 2003;53:1354https://doi.org/10.1227/01.neu.0000093200.74828.2f.

40. McLain RF, Sparling E, Benson DR. Early failure of short-segment pedicle instrumentation for thoracolumbar fractures. A preliminary report. J Bone Joint Surg Am. 1993;75(2):162-7. 
https://doi.org/10.2106/00004623-199302000-000

41. Verlaan JJ, Diekerhof CH, Buskens E, van der Tweel I, Verbout AJ, Dhert WJ, Oner FC. Surgical treatment of traumatic fractures of the thoracic and lumbar spine: a systematic review of the literature on techniques, complications, and outcome. Spine. 2004;29(7):803-14. https://doi.org/10.1097/01.brs.0000116990.31984.a9.

42. Eck JC, Nachtigall D, Humphreys SC, Hodges SD. Comparison of vertebroplasty and balloon kyphoplasty for treatment of vertebral compression fractures: a meta-analysis of the literature. Spine J. 2008;8(3):488-97.

43. Kim DH, Vaccaro AR. Osteoporotic compression fractures of the spine; current options and considerations for treatment. Spine J. 2006;6:479-87.

44. Farahvar A, Dubensky D, Bakos R. Perforation of the right cardiac ventricular wall by polymethylmethacrylate after lumbar kypho- plasty. J Neurosurg Spine. 2009;11:487-91. https://doi.org/10.3171/2009.5.SPINE08517.

45. Cao Z, Wang M, Meng QQ. Comparison of clinical efficacy of transpedicular bone grafting combined with pedicle screw internal fixation versus simply pedicle screw internal fixation in the treatment of thoracolumbar burst fractures. J Pract Med. 2018;34:2692-5.

https://doi.org/10.2214/ajr.183.4.1831097.

\section{Tables}

Due to technical limitations, table 1 is only available as a download in the Supplemental Files section.

\section{Figures}




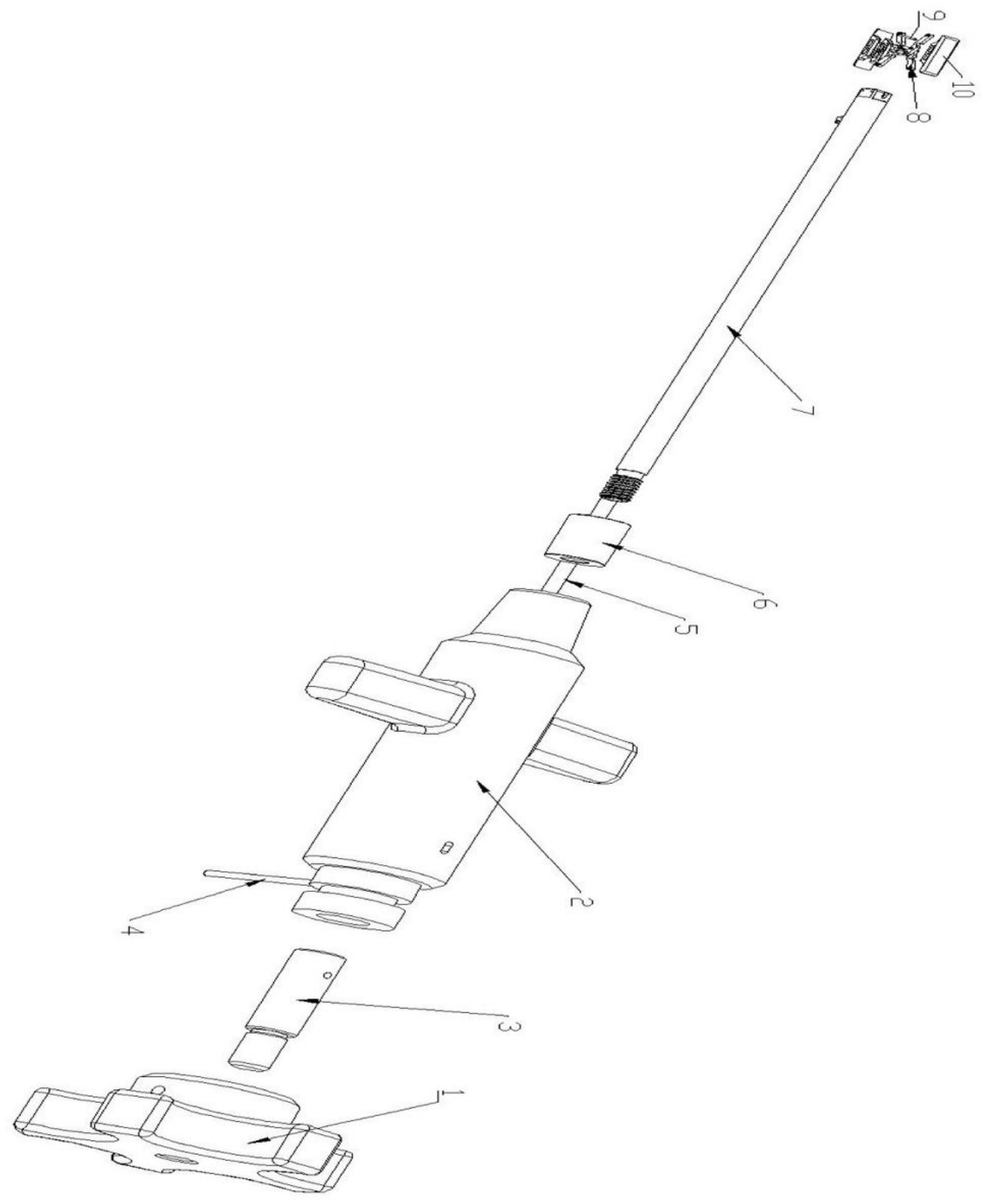

Figure 1

Structural diagram of the new type of transpedicular reducer 


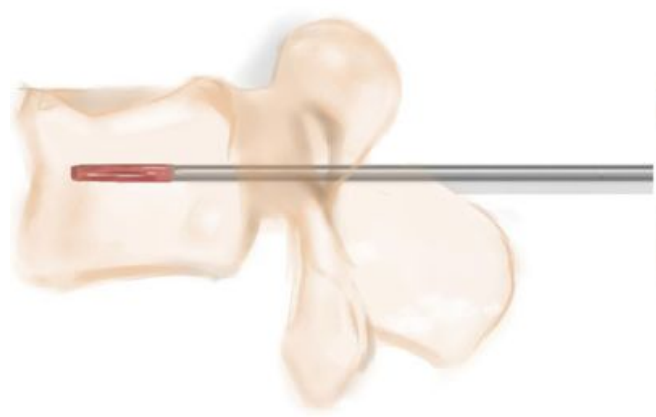

a

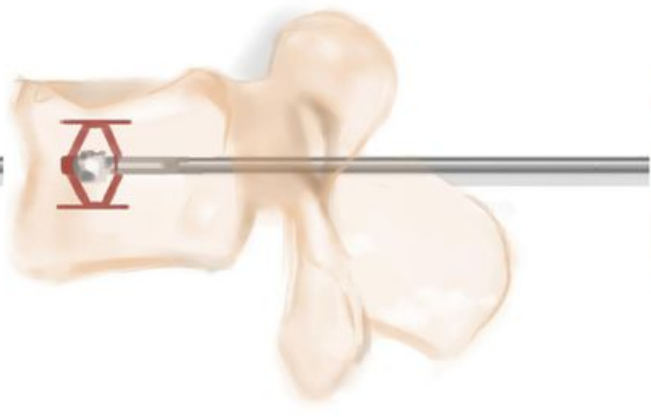

b

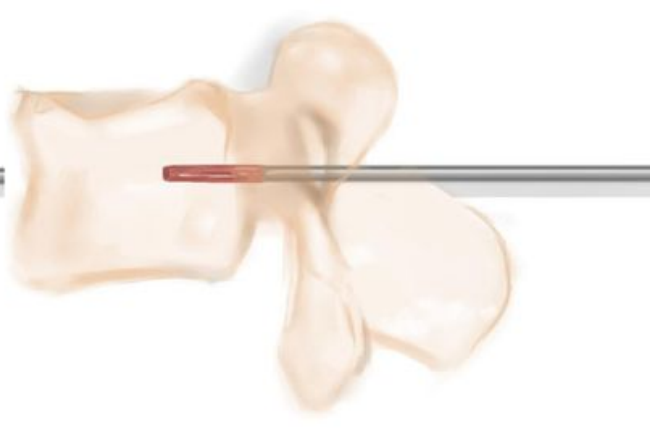

C

\section{Figure 2}

Schematic diagram of the strategic design for the application of the new transpedicular reducer to a vertebral burst fracture. A: the new transpedicular reducer enters the fracture through the pedicle; $B$ : performs open reduction; and C: closes and exits the injured vertebra
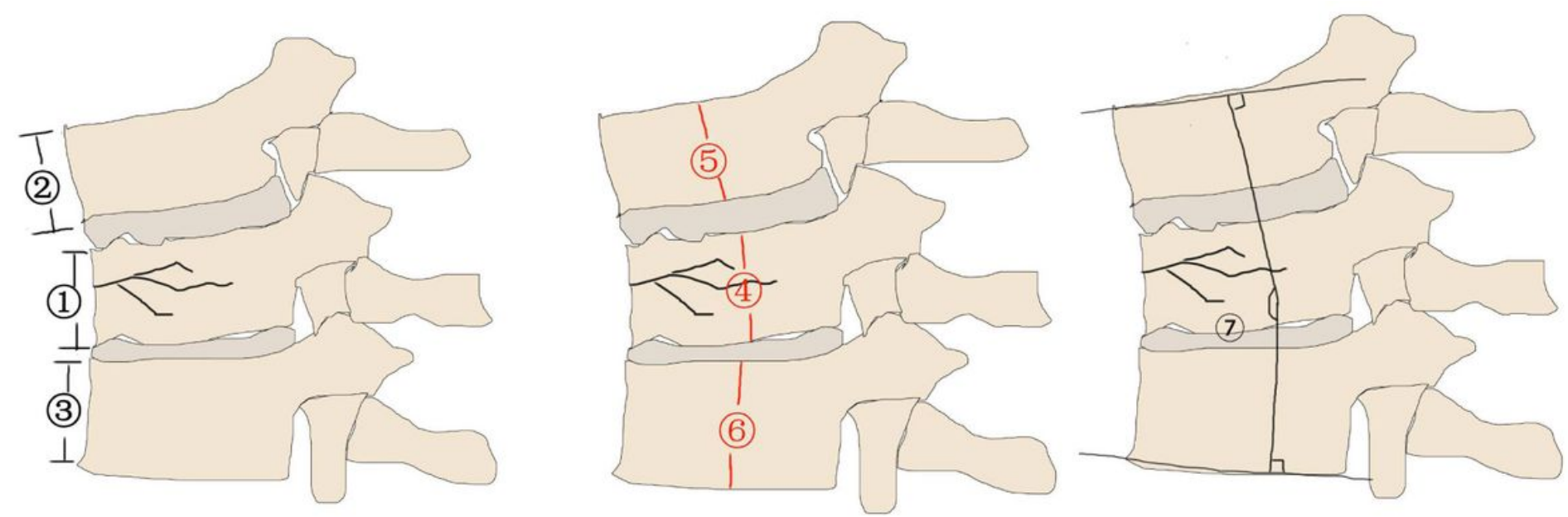

Figure 3

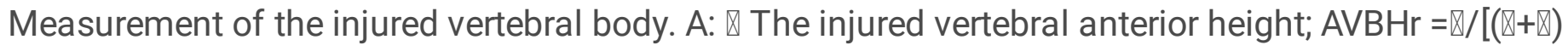

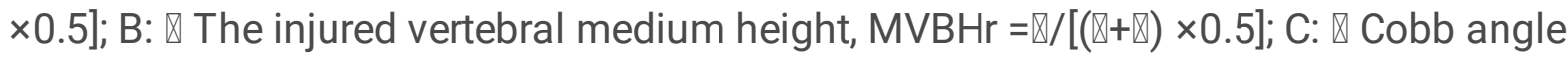




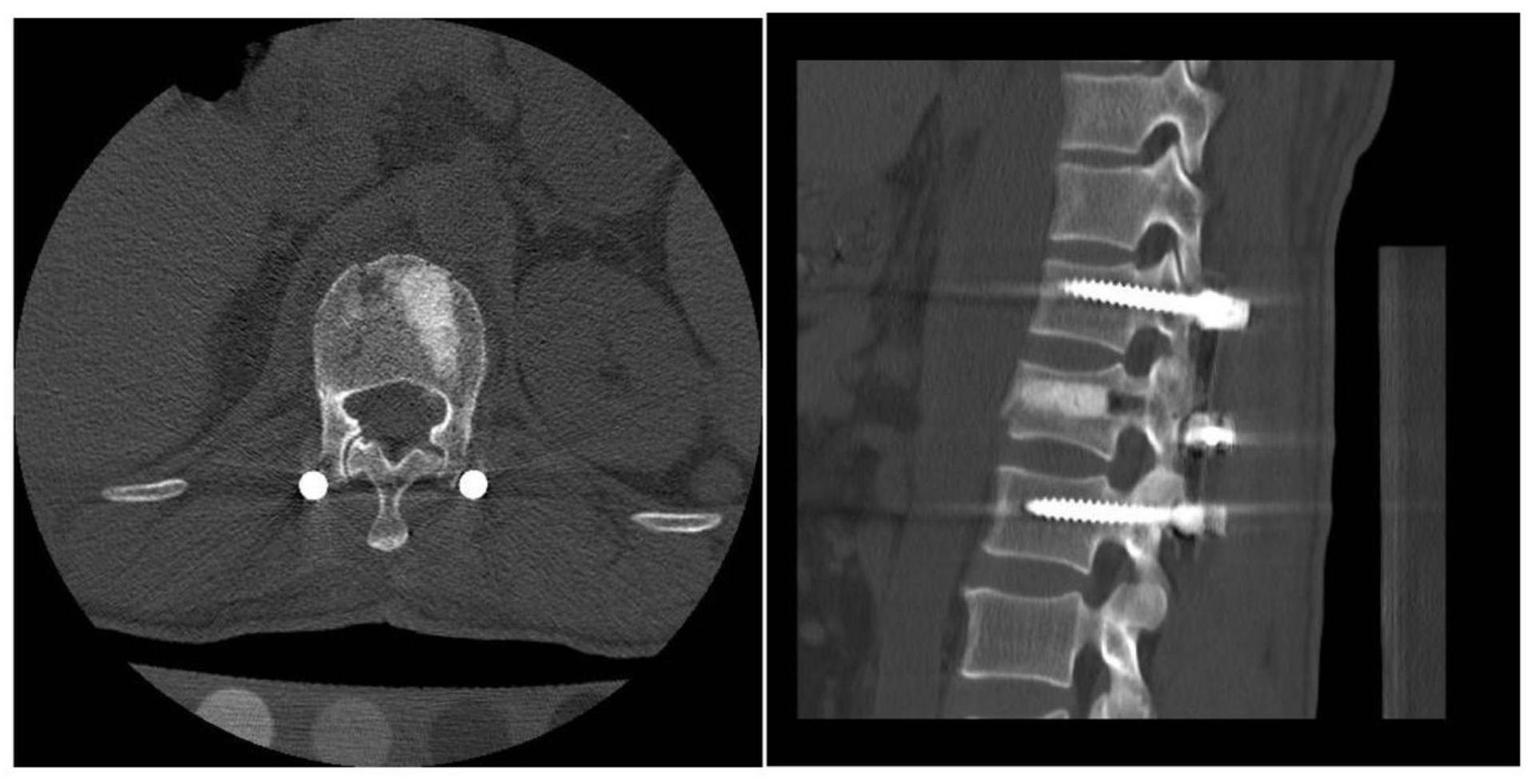

\section{Figure 4}

Coronal and sagittal CT 3 days after the operation. Allograft bone was evenly wedged into the anterior and medial columns of the fractured vertebra 


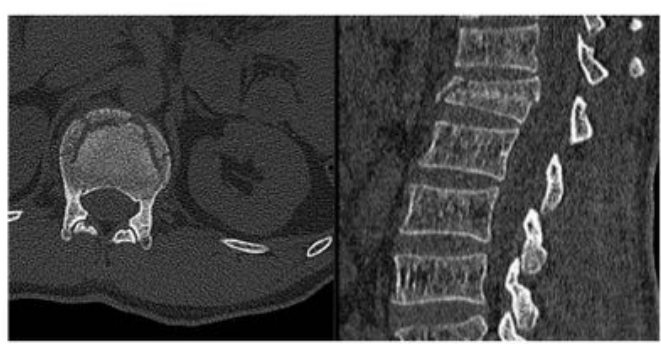

A

B

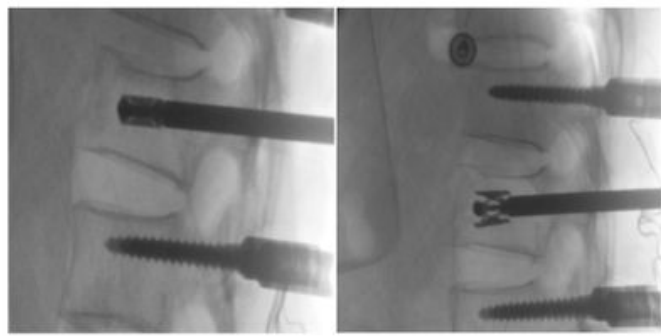

C

D
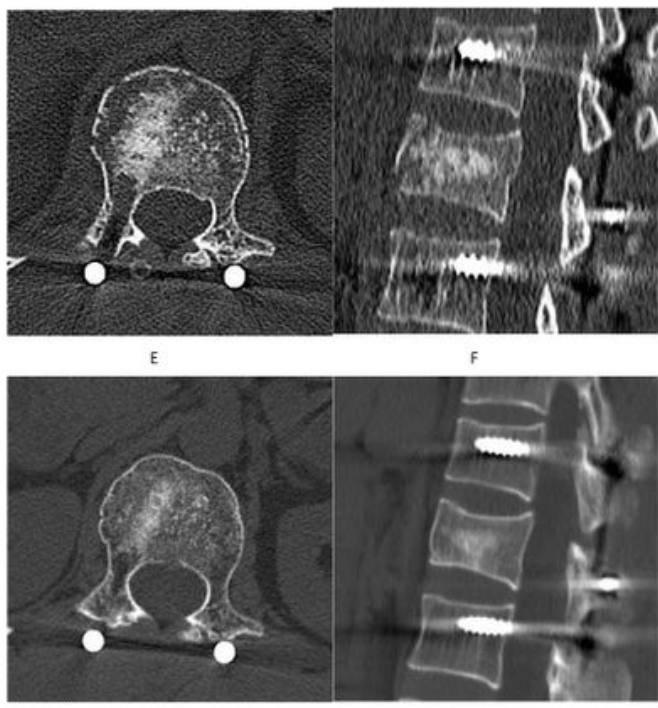

H

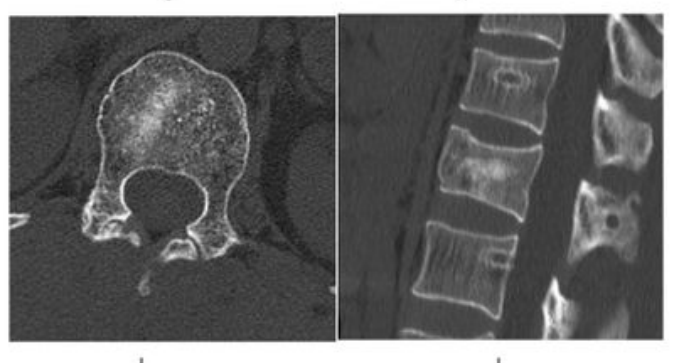

\section{Figure 5}

Imaging data of typical patient before,during and after operation A, B: Preoperative coronal and sagittal CT demonstrating a burst fracture of the vertebral body. C, D: During the operation, the new transpedicular reducer was used to reset the injured vertebra. E, F: Coronal and sagittal CT 3 days after the operation showing that the allograft was evenly wedged into the anterior and medial columns. G, H: Coronal and sagittal CT 12 months after the operation. The allograft bone that had filled the anterior and middle 
columns was partially absorbed, no defects were found, and the trabecular structure was visible in the cancellous bone. I, J: Coronal and sagittal CT after removal of the internal fixation

\section{Supplementary Files}

This is a list of supplementary files associated with this preprint. Click to download.

- table1.xls 